\title{
Large-scale physical disabilities and their management in the aftermath of the 2005 earthquake in Pakistan
}

\author{
M. Mallick, ${ }^{1}$ J.K. Aurakzai, ${ }^{2}$ K.M. Bile and N. Ahmed ${ }^{3}$
}

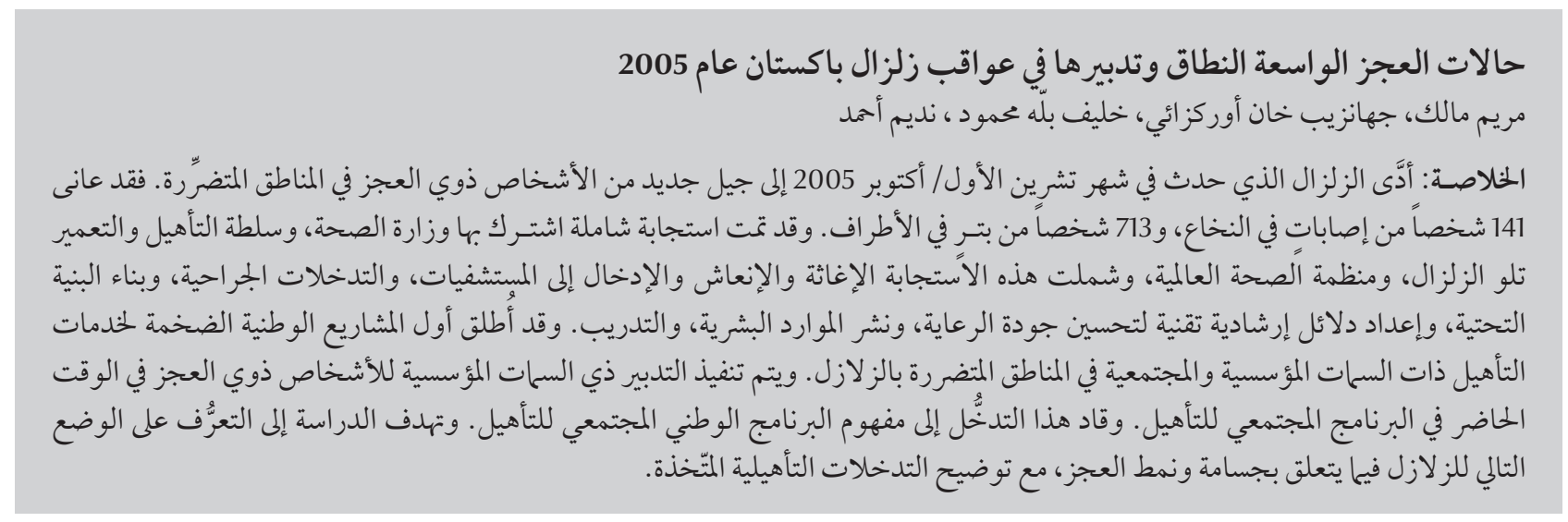

ABSTRACT The October 2005 earthquake in Pakistan created a new generation of "persons with disabilities" (PWDs) in the affected districts. A total of 741 people suffered spinal injuries while 713 underwent amputations. A comprehensive response was launched jointly by the Ministry of Health, Earthquake Reconstruction and Rehabilitation Authority and the World Health Organization involving rescue and recovery, hospitalization, surgical interventions, building of infrastructure, development of technical guidelines to improve quality of care, human resource deployment and training. The first national megaproject for institutional and community-based rehabilitation (CBR) services was launched in the earthquake-affected areas. The institutional management of PWDs is now carried out alongside the CBR programme. This intervention also led to the concept of a national CBR programme. The study aims to identify the post-earthquake situation regarding the magnitude and type of physical disabilities and to highlight the rehabilitative interventions undertaken.

L'incapacité physique à grande échelle et sa prise en charge à la suite du tremblement de terre de 2005 au Pakistan

RÉSUMÉ Le tremblement de terre survenu en octobre 2005 au Pakistan a entraîné l'apparition d'une nouvelle génération de personnes handicapées dans les districts touchés. Au total, 741 personnes ont été victimes de traumatismes médullaires et 713 ont subi une amputation. Le ministère de la Santé, l'Autorité chargée de la reconstruction et de la remise en état après le séisme [Earthquake Reconstruction and Rehabilitation Authority] et I'Organisation mondiale de la Santé ont organisé conjointement une riposte complète, comprenant des opérations de secours, de relèvement et d'hospitalisation, des interventions chirurgicales, la construction d'infrastructures, l'élaboration de directives techniques sur l'amélioration de la qualité des soins, et le déploiement et la formation de personnel. Le premier projet national de grande ampleur pour les services de réadaptation institutionnels et communautaires a été lancé dans les zones touchées. La prise en charge institutionnelle des personnes handicapées est désormais assurée en commun avec le programme de services communautaires de réadaptation. Cette intervention a également débouché sur le concept de programme national de réadaptation communautaire. L'objectif de cette étude est de décrire la situation consécutive au tremblement de terre, notamment l'ampleur et le type d'incapacités physiques, et de souligner les interventions de réadaptation engagées.

${ }^{7}$ World Health Organization, Country Office, Islamabad, Pakistan (Correspondence to M. Mallick: mallickm@pak.emro.who.int). ${ }^{2}$ National Health Emergency Preparedness and Response, Islamabad, Pakistan.

${ }^{3}$ National Disaster Management Authority, Islamabad, Pakistan. 


\section{Introduction}

An estimated 650 million people live with disabilities around the world, $80 \%$ of whom are living in low-income countries with limited or no access to basic health services including rehabilitation services [1].The link between conflict, emergency situations and disability is incontrovertible as conflict and natural disasters are a significant cause of impairment due to increased rates of injury, lack of medical care and disruption of medical health care services [2].

The 40-second duration of the 8 October 2005 south Asian earthquake emerged as the most devastating natural disaster in the history of Pakistan and the region over the past century. While the huge death toll exceeding 73338 was overwhelming, an estimated 3.5 million people were rendered homeless and another 128309 sustained serious causalities, including spinal injuries and limb trauma, some leading to amputations $[3,4]$.

In many rural communities of $\mathrm{Pa}$ kistan, disabilities among household members are normally concealed, especially those acquired from birth or developed soon thereafter [5]. As a result, socioeconomic data regarding disabilities are not well documented. According to the 1998 population census, persons with disabilities (PWDs) constituted approximately 3.287 million (2.49\%), including all types of disability [6], which was significantly lower than the World Health Organization (WHO) estimate of 10\% [7]. This can be attributed to the varying definitions of disabilities, methodology used and the limited capacity for data collection at the national level.

Additionally, there are only a few fragmented programmes and services that address the needs of PWDs, most of which are primarily confined to urban areas, resulting in considerable socioeconomic burden evidenced by the limited access to health, education and employment opportunities. Disability- inclusive legislation capable of integrating a disability dimension at the national level also did not exist in the country prior to the 1980s.

Following the United Nation's declaration of 1981 as the International Year of the Disabled and 1983-1992 as the Decade of the Disabled, the first disability-specific sectoral legislation was promulgated by the Government of Pakistan, consisting of the Disabled Persons Employment and Rehabilitation Ordinance 1981. Thereafter, a national policy for PWDs was formalized in 2002 by the Ministry of Social Welfare and Special Education, whose National Plan of Action is currently under implementation. In September 2008, Pakistan became a signatory to the UN Convention on the Rights of Persons with Disabilities, which outlines the obligation of states to protect and ensure the safety of people with disabilities in situations of risk, including armed conflict [8].

Though the concept of medical rehabilitation was introduced in Pakistan during the late 1990s, only a few public sector institutions provide comprehensive rehabilitative services. Current estimates show that in developing countries only $2 \%$ of PWDs receive some form of rehabilitation assistance [9].

The Government has taken certain tangible measures by establishing comprehensive rehabilitation services such as special computerized identity cards for PWDs, free medical treatment at government hospitals, and implementation of a $2 \%$ quota for their employment. However, the implementation rate of such initiatives remains very low. The Pakistan welfare fund Bait ul Maal was established in 1992 for the provision of social services to PWDs along with other marginalized members of the society. PWDs also benefit from the welfare fund of Zakat and from the recently launched Benazir Income Support Programme. An education quota of $1 \%$ for PWDs has been recommended by the Higher Education Commission for all universities, along with their eligibility to participate in competitive employment exams within their allotted quota of $2 \%$.

The above-mentioned initiatives notwithstanding, service delivery capacity in terms of rehabilitation measures remained highly institutionalized with a top-down approach. The community's vital role in the provision of rehabilitative services was recognized only in the aftermath of the October 2005 earthquake, resulting in the launch of the first community-based rehabilitation (CBR) programme in the country.

The objective of this paper is to evaluate the magnitude and types of post-earthquake physical disabilities, assess their consequent rehabilitative needs and highlight the efforts made during the relief and recovery phase for the provision of comprehensive rehabilitative services for PWDs.

\section{Methods}

Data regarding major disabilities involving spinal cord injuries and amputations were retrospectively collected in October and November 2005 to assess the magnitude of the problem. A standard questionnaire was developed for data collection and several visits conducted to major hospitals in urban cities, field hospitals and camps in the affected districts. Detailed interviews were also conducted with health managers, district administrators and patients in the provinces of Khyber-Pakhtunkhwa and Punjab, in addition to the Pakistan-administered Kashmir (PAK) territory. A total of 20 health facilities for spinal cord injuries and 36 facilities for amputations were visited. On completion of data collection and verification from all the districts, a reconciliation exercise was initiated to eliminate duplications. Finally, the cumulative figures of 741 for spinal cord injuries and 713 for amputations resulting from earthquake hazard were compiled and analysed. For a tangible number of these patients, their age and 
level of spinal injuries and amputations were not effectively documented.

\section{Results}

According to the data collected for this study, a total of 741 spinal injury cases, with and without neurological deficit, were received in major hospitals in Rawalpindi, Islamabad, Lahore and Peshawar in October 2005 related to the earthquake, and another 713 cases experienced various kinds of limb trauma leading to major and minor amputations.

Table 1 shows the spinal injuries detected and amputations carried out post earthquake by age and gender. The majority of the spinal injury cases were females $(62 \%)$ and the predominant age group was $>18-40$ years (57\%). In $12 \%$ of the spinal injury cases, the age of the patient could not be ascertained. Similar to spinal injuries, the majority of amputations were undertaken in females (51.3\%) while the predominant age groups were $>18-40$ years $(33.3 \%)$ and $5-18$ years $(31.26 \%)$ with $6 \%$ of the total under 5 years old; in 13\% of the cases age could not be ascertained.

Table 2 lists the amputations carried out by age, gender and level of amputations. Out of 713 total amputations, 423 (59\%) were lower-limb amputations and 290 (41\%) were upper-limb amputations. Of the lower-limb amputations undertaken, 389 (91\%) were major amputations: 179 (42\%) were transtibial (below knee) amputations while 65 (15\%) were transfemoral (above knee) amputations and feet were surgically removed in $67(16 \%)$ cases. Seventy eight (18\%) cases were simply labelled as leg amputations, without being disaggregated as transfemoral or transtibial amputations owing to inadequate documentation.

Of the upper-limb amputations carried out, 192 (66\%) were recorded as major upper-limb amputations, including 116 (40\%) transhumeral (above elbow), 40 (14\%) transradial (below elbow) and 36 (12\%) hand amputations. In 65 cases, it was recorded that the dominant right upper limb was amputated, which aggravated patients' functional limitations and caused them difficulty in performing activities of daily living.

Table 3 provides details about the level of post-earthquake spinal injuries. Among the 741 spinal cases, a total of 916 injuries were reported. This difference was due to multiple-level fractures involving the cervical, thoracic, lumbar and sacral vertebral column. Out of the total of 741 cases, $71.2 \%$ developed some neurological deficit resulting in complete or partial paraplegia or quadriplegia. However, among the 50 cases with cervical injury, only 13 cases developed incomplete quadriplegia while the remaining patients survived without any neurological deficit.
Of the 916 recorded injuries, the greatest share, 443 cases (48.4\%) were at the lumbar level, followed by 301 (32.9\%) cases at the thoracic level, while cervical injuries constituted only 5.4\% (50 cases) of the surviving cases with spinal injuries. Only $0.6 \%$ of the cases experienced sacral injuries, while in $12.8 \%$ of the cases the level of the injury was neither documented nor ascertainable. Figure 1 illustrates the geographic distribution of spinal cord injuries and amputations by district of origin. The highest percentage of patients with spinal cord injuries (46\%) originated from Muzaffarabad district, which was also the district with the greatest devastation, followed by Mansehra (20\%) and Bagh (18\%). A similar pattern was observed with regard to amputations carried out, with 36\% of these in Muzaffarabad, $22 \%$ in Mansehra and 16\% in Bagh.

The capacity of tertiary-level hospitals in terms of provision of rehabilitative services was suboptimal considering the massive requirements of the catastrophe and included a shortage of trained health professionals and necessary equipment. As a result, these patients were scattered across different wards, corridors and makeshift arrangements in various hospitals, leading to pressure sores, urinary tract infections and deep vein thrombosis.

In order to cater to the immediate needs, a young cadre of 57 males and females was given a short, 2 -week training

\begin{tabular}{|c|c|c|c|c|c|c|c|c|c|c|c|c|c|}
\hline \multirow[t]{3}{*}{ Injury } & & \multicolumn{10}{|c|}{ Age group (years) } & & \\
\hline & & \multicolumn{2}{|c|}{$<5$} & \multicolumn{2}{|c|}{$5-18$} & \multicolumn{2}{|c|}{$>18-40$} & \multicolumn{2}{|c|}{$>40$} & \multicolumn{2}{|c|}{ Not listed } & \multicolumn{2}{|c|}{ Total } \\
\hline & & No. & $\%$ & No. & $\%$ & No. & $\%$ & No. & $\%$ & No. & $\%$ & No. & $\%$ \\
\hline \multirow{2}{*}{$\begin{array}{l}\text { Spinal cord } \\
\text { injury }\end{array}$} & M & 3 & 0.40 & 40 & 5.40 & 165 & 22.27 & 40 & 5.40 & 37 & 4.99 & 285 & 38.46 \\
\hline & $\mathrm{F}$ & 3 & 0.40 & 104 & 14.04 & 257 & 34.68 & 38 & 5.13 & 54 & 7.29 & 456 & 61.54 \\
\hline \multirow[t]{2}{*}{ Amputation } & M & 19 & 2.66 & 113 & 15.84 & 103 & 14.44 & 61 & 8.55 & 51 & 7.15 & 347 & 48.66 \\
\hline & $\mathrm{F}$ & 24 & 3.36 & 110 & 15.42 & 135 & 18.93 & 53 & 7.43 & 44 & 6.17 & 366 & 51.33 \\
\hline \multirow[t]{3}{*}{ Total } & M & 22 & 1.51 & 153 & 10.52 & 268 & 18.43 & 101 & 6.95 & 88 & 6.05 & 632 & 43.47 \\
\hline & $\mathrm{F}$ & 27 & 1.86 & 214 & 14.72 & 392 & 26.96 & 91 & 6.26 & 98 & 6.74 & 822 & 56.53 \\
\hline & Total & 49 & 3.37 & 367 & 25.24 & 660 & 45.39 & 192 & 13.20 & 186 & 12.79 & 1454 & 100 \\
\hline
\end{tabular}

$M=$ male $;=$ female. 


\begin{tabular}{|c|c|c|c|c|c|c|c|c|c|c|c|}
\hline \multirow{3}{*}{\multicolumn{2}{|c|}{ Type of amputation }} & \multicolumn{8}{|c|}{ Age group (years) } & \multirow{2}{*}{\multicolumn{2}{|c|}{ Total }} \\
\hline & & \multicolumn{2}{|c|}{$<5$} & \multicolumn{2}{|c|}{$5-18$} & \multicolumn{2}{|c|}{$>18$} & \multicolumn{2}{|c|}{ Not listed } & & \\
\hline & & No. & $\%$ & No. & $\%$ & No. & $\%$ & No. & $\%$ & No. & $\%$ \\
\hline \multicolumn{12}{|l|}{ Lower-limb } \\
\hline \multirow[t]{2}{*}{ Transfemoral } & M & 1 & 0.14 & 9 & 1.26 & 15 & 2.10 & 1 & 0.14 & 26 & 3.65 \\
\hline & $\mathrm{F}$ & 1 & 0.14 & 11 & 1.54 & 24 & 3.37 & 3 & 0.42 & 39 & 5.47 \\
\hline \multirow[t]{2}{*}{ Transtibial } & M & 4 & 0.56 & 33 & 4.63 & 45 & 6.31 & 6 & 0.84 & 88 & 12.34 \\
\hline & $\mathrm{F}$ & 7 & 0.98 & 26 & 3.65 & 48 & 6.73 & 10 & 1.40 & 91 & 12.76 \\
\hline \multirow[t]{2}{*}{ Leg amputation } & M & 3 & 0.42 & 17 & 2.38 & 16 & 2.24 & 8 & 1.12 & 44 & 6.17 \\
\hline & $\mathrm{F}$ & 0 & 0.00 & 8 & 1.12 & 22 & 3.09 & 4 & 0.56 & 34 & 4.77 \\
\hline \multirow{2}{*}{$\begin{array}{l}\text { Foot } \\
\text { amputation }\end{array}$} & M & 2 & 0.28 & 12 & 1.68 & 10 & 1.40 & 6 & 0.84 & 30 & 4.21 \\
\hline & $\mathrm{F}$ & 5 & 0.70 & 9 & 1.26 & 17 & 2.38 & 6 & 0.84 & 37 & 5.19 \\
\hline \multirow[t]{2}{*}{ Foot digits } & M & 1 & 0.14 & 3 & 0.42 & 9 & 1.26 & 5 & 0.70 & 18 & 2.52 \\
\hline & $\mathrm{F}$ & 0 & 0.00 & 7 & 0.98 & 8 & 1.12 & 1 & 0.14 & 16 & 2.24 \\
\hline Subtotal & & 24 & 3.36 & 135 & 18.92 & 214 & 30.01 & 50 & 7.01 & 423 & 59.32 \\
\hline \multicolumn{12}{|l|}{ Upper-limb } \\
\hline \multirow[t]{2}{*}{ Transhumeral } & M & 2 & 0.28 & 14 & 1.96 & 27 & 3.79 & 9 & 1.26 & 52 & 7.29 \\
\hline & $\mathrm{F}$ & 2 & 0.28 & 17 & 2.38 & 37 & 5.19 & 8 & 1.12 & 64 & 8.98 \\
\hline \multirow[t]{2}{*}{ Transradial } & M & 1 & 0.14 & 3 & 0.42 & 9 & 1.26 & 4 & 0.56 & 17 & 2.38 \\
\hline & $\mathrm{F}$ & 1 & 0.14 & 10 & 1.40 & 10 & 1.40 & 2 & 0.28 & 23 & 3.23 \\
\hline \multirow{2}{*}{$\begin{array}{l}\text { Hand } \\
\text { amputation }\end{array}$} & M & 3 & 0.42 & 6 & 0.84 & 9 & 1.26 & 1 & 0.14 & 19 & 2.66 \\
\hline & $\mathrm{F}$ & 1 & 0.14 & 8 & 1.12 & 6 & 0.84 & 2 & 0.28 & 17 & 2.38 \\
\hline \multirow[t]{2}{*}{ Hand digits } & M & 2 & 0.28 & 12 & 1.68 & 15 & 2.10 & 5 & 0.70 & 34 & 4.77 \\
\hline & $\mathrm{F}$ & 7 & 0.98 & 11 & 1.54 & 11 & 1.54 & 3 & 0.42 & 32 & 4.49 \\
\hline \multirow{2}{*}{$\begin{array}{l}\text { Type not } \\
\text { ascertainable }\end{array}$} & M & 0 & 0.00 & 4 & 0.56 & 9 & 1.26 & 6 & 0.84 & 19 & 2.66 \\
\hline & $\mathrm{F}$ & 0 & 0.00 & 3 & 0.42 & 5 & 0.70 & 5 & 0.70 & 13 & 1.82 \\
\hline Subtotal & & 19 & 2.66 & 88 & 12.32 & 138 & 19.34 & 45 & 6.3 & 290 & 40.66 \\
\hline \multirow[t]{3}{*}{ Grand total } & M & 19 & 2.66 & 113 & 15.85 & 164 & 23.00 & 51 & 7.15 & 347 & 48.67 \\
\hline & $\mathrm{F}$ & 24 & 3.37 & 110 & 15.43 & 188 & 26.37 & 44 & 6.17 & 366 & 51.33 \\
\hline & Total & 43 & 6.03 & 223 & 31.28 & 352 & 49.37 & 95 & 13.32 & 713 & 100 \\
\hline
\end{tabular}

$M=$ male $;=$ female .

course in basic rehabilitation techniques for the prevention of secondary complications, in collaboration with the nongovernmental organization Handicap International in October 2005. This initiative provided services for spinal injury patients, especially for those who underwent spinal fixation in major hospitals of Islamabad/ Rawalpindi, and presumably averted many impending complications including pressure sores, muscle wasting and contractures in the patients.

The Federal Ministry of Health upgraded and strengthened the National Institute for Rehabilitation Medicine
(NIRM), Pakistan Institute of Medical Sciences (PIMS) Satellite Centre and Cantonment General Hospital Rawalpindi by inducting 100 doctors, 100 physiotherapists and 50 psychologists in December 2005. WHO and United Nations Children's Fund (UNICEF) established 100-bedded prefabricated spinal injury units at PIMS Satellite Centre and NIRM in December 2005 and January 2006, respectively, where all the spinal injury patients were subsequently moved. A comprehensive rehabilitation plan was developed for each spinal injury patient, according to his or her type and level of disability, and the rehabilitation process was initiated through a multidisciplinary approach.

The skills of the newly recruited staff were enhanced through training workshops and certificate courses conducted at NIRM. The acute shortage of occupational therapists was addressed by organizing a 3-week training course for paramedics using a special curriculum developed for this purpose.

WHO training manuals on promoting independence following spinal cord injuries were adapted and translated, in order to provide the necessary skills 


\begin{tabular}{|c|c|c|c|c|c|c|c|c|c|c|c|}
\hline \multirow[t]{3}{*}{ Level of injury } & & \multicolumn{8}{|c|}{ Age group (years) } & \multirow{2}{*}{\multicolumn{2}{|c|}{ Total }} \\
\hline & & \multicolumn{2}{|c|}{$<5$} & \multicolumn{2}{|c|}{$5-18$} & \multicolumn{2}{|c|}{$>18$} & \multicolumn{2}{|c|}{ Not listed } & & \\
\hline & & No. & $\%$ & No. & $\%$ & No. & $\%$ & No. & $\%$ & No. & $\%$ \\
\hline \multirow[t]{2}{*}{ Cervical } & M & 0 & 0.00 & 2 & 0.22 & 13 & 1.42 & 5 & 0.55 & 20 & 2.18 \\
\hline & $\mathrm{F}$ & 0 & 0.00 & 8 & 0.87 & 16 & 1.75 & 6 & 0.66 & 30 & 3.28 \\
\hline \multirow[t]{2}{*}{ Thoracic } & M & 0 & 0.00 & 21 & 2.29 & 97 & 10.59 & 10 & 1.09 & 128 & 13.97 \\
\hline & $\mathrm{F}$ & 1 & 0.11 & 28 & 3.06 & 128 & 13.97 & 16 & 1.75 & 173 & 18.89 \\
\hline \multirow[t]{2}{*}{ Lumbar } & M & 2 & 0.22 & 30 & 3.28 & 110 & 12.01 & 23 & 2.51 & 165 & 18.01 \\
\hline & $\mathrm{F}$ & 1 & 0.11 & 66 & 7.21 & 176 & 19.21 & 35 & 3.82 & 278 & 30.35 \\
\hline \multirow[t]{2}{*}{ Sacral } & M & 0 & 0.00 & 0 & 0.00 & 2 & 0.22 & 0 & 0.00 & 2 & 0.22 \\
\hline & $\mathrm{F}$ & 0 & 0.00 & 0 & 0.00 & 3 & 0.33 & 0 & 0.00 & 3 & 0.33 \\
\hline \multirow[t]{2}{*}{ Not ascertainable } & M & 2 & 0.22 & 4 & 0.44 & 34 & 3.71 & 7 & 0.76 & 47 & 5.13 \\
\hline & $\mathrm{F}$ & 2 & 0.22 & 22 & 2.40 & 42 & 4.59 & 4 & 0.44 & 70 & 7.64 \\
\hline \multirow[t]{3}{*}{ Total } & M & 4 & 0.44 & 57 & 6.22 & 256 & 27.95 & 45 & 4.91 & 362 & 39.52 \\
\hline & $\mathrm{F}$ & 4 & 0.44 & 124 & 13.54 & 365 & 39.85 & 61 & 6.66 & 554 & 60.48 \\
\hline & Total & 8 & 0.87 & 181 & 19.76 & 621 & 67.79 & 106 & 11.57 & 916 & 100.00 \\
\hline
\end{tabular}

$M=$ male $;=$ female

to mid-level health professionals. A manual was also developed for patients and their families, enabling them to cope with their physical limitations and increase their independence by enhancing their existing potential. Another manual was compiled which provided guidelines/designs for accessibility of wheel chairs in public buildings as well as in houses. In pursuance of directives of the Earthquake Reconstruction and Rehabilitation Authority, the guidelines provided in this manual were incorporated into the reconstruction plan of the earthquake-affected districts by National Engineering Service Pakistan.
As the Artificial Limb Centre at the Fauji Foundation Hospital was the only public sector hospital providing prosthetic (an artificial substitute for a missing body part, such as an arm, leg, eye, or tooth, used for functional or cosmetic reasons) and orthotic (an orthopaedic appliance or apparatus used to support,

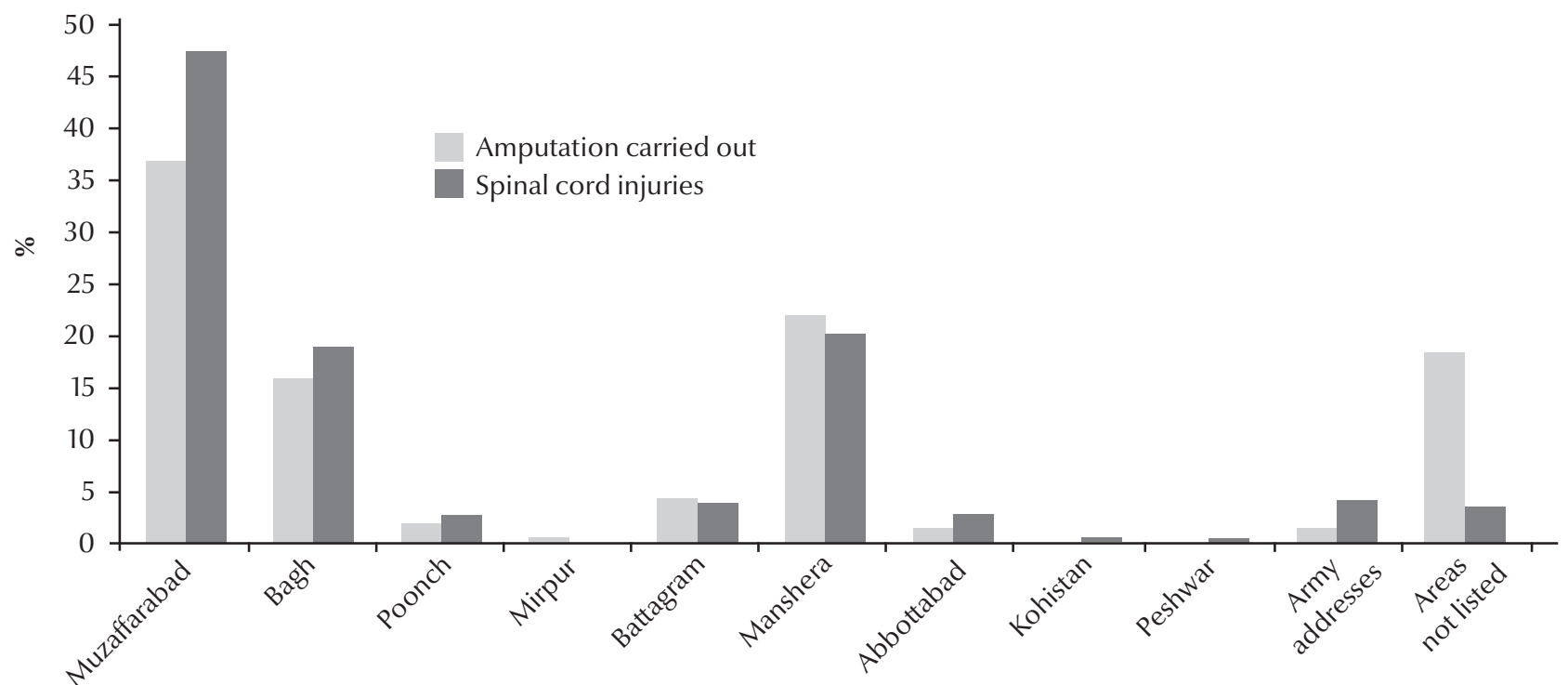

District of origin 
align, prevent deformities to improve function of movable parts of the body) services in the twin cities of Rawalpindi/ Islamabad, the provision of prosthesis to amputees was facing capacity limitations in meeting the increasing demand generated by newly amputated patients. Accordingly, a number of cases were also referred to the Pakistan Institute of Prosthetic and Orthotic Sciences in Peshawar, which subsequently established five satellite centres in the earthquake-affected districts. A total of 11 prosthetic and orthotic workshops were established by various national and international organizations for the provision of prosthetic and orthotic services in the disaster-hit districts;

\section{Table 4 Post-earthquake initiatives for the provision of rehabilitation services to people with disabilities (PWDs), development of infrastructure and implemented capacity-building interventions}

$\begin{array}{lr}\text { Outcomes } & \text { Value } \\ \text { Rehabilitation outcome } & \\ \text { Independence in activities of daily living of spinal cord injury } & 62 \% \\ \text { patients } & 5 \% \\ \text { Spinal cord injury patients provided with livelihood } & 100 \% \\ \text { Provision of lower-limb prosthetic devices to amputees } & 8 \% \\ \text { Amputees provided with livelihood } & \end{array}$

\section{Provision of medical rehabilitation services}

Number of PWDs provided with rehabilitation services

Number of therapeutic sessions (speech, physiotherapy, psychology)

\section{Provision of assistive devices}

Wheel chairs, spinal jackets, commodes, chairs, crutches, walkers, hearing aids, low-vision aids, etc.

\section{Livelihood provided to PWDs}

Number of PWDs provided with livelihood

Share of PWD in employment opportunities.

\section{Inclusive education}

Number of children with disabilities enrolled for inclusive education

\section{Infrastructure}

100-bedded spinal injury units established at Islamabad

50-bedded rehabilitation centres established at Khyber-

Pakhtoonkhwa and Azad Jammu \& Kashmir

Basic rehabilitation units in earthquake-affected districts

Resource information centres for CBR in earthquake-affected areas

\section{Recruitment of health/rehabilitation professionals for 3 years}

Doctors, nurses, physiotherapists, speech therapists, psychologists

Community rehabilitation workers for CBR programmes

\section{Development of training manuals}

Management of spinal cord injuries

Training manuals for CBR

\section{Trainings sessions}

Training session each of 30 days for community rehabilitation workers

Awareness-raising workshops

Training workshops for health/rehabilitation professionals

$C B R=$ community-based rehabilitation however, the majority of the services offered were for lower-limb prosthesis only.

The major challenges that emerged were the provision of long-term sustainable support for PWDs in their districts of origin, as well as improving their quality of life in terms of disability awareness and social, economic and cultural inclusion. An innovative strategy envisaging a combination of community- and institution-based rehabilitation was introduced by $\mathrm{WHO}$ and the Ministry of Health for both pre- and post-earthquake PWDs. This strategy is being implemented by the Earthquake Reconstruction and Rehabilitation Authority through the Medical Rehabilitation of the Persons with Disabilities in the Earthquake Affected Areas project, with $\mathrm{WHO}$ technical assistance.

Table 4 illustrates the post-earthquake initiatives undertaken for the provision of rehabilitation services to PWDs, including, health, education, livelihood and empowerment. It also gives details regarding development of infrastructure and implemented capacity-building interventions, including recruitment and training of rehabilitation professionals and development of training manuals.

\section{Discussion}

In humanitarian emergency situations, disasters disproportionately impact persons with existing disability and create a new generation of persons with functional limitations in constant need of rehabilitative services [10]. The most common disabilities following the earthquake in Pakistan were spinal injuries and those requiring amputations. The number of spinal cord injuries in the aftermath of the October 2005 earthquake in Pakistan were the highest among injuries reported in earthquakes occurring in other countries [11]. The reason for this can be attributed to several factors, including the mode 
of evacuation, deficient seismic-proof building codes and the highly diversified rugged mountainous terrain, in addition to the magnitude of the disastrous earthquake of Pakistan.

Prehospital management of spinal injury is of critical importance since $25 \%$ of spinal cord injury damage may occur, or can be aggravated, after the initial event [12]. The first to respond after the earthquake in Pakistan were usually untrained local community members, being unaware of the importance of spinal immobilization to prevent secondary neurological damage, although they worked frantically to rescue as many people as possible. The use of a spinal board is considered to be an integral part of the standard operating procedures for evacuation and transport of spinal cord injury patients. On the contrary, spinal cord injury patients were dragged and pulled out of the rubble and carried in a manner not conforming to international standards of transferring such patients. A similar practice of rescue and recovery of spinal cord injury patients was also observed in the earthquake of Bam, Islamic Republic of Iran in December, 2003 [13].

Most patients with incomplete spinal cord injuries reported that they were able to move their limbs while buried under the rubble, but during shifting to health facilities, their limbs were completely paralysed [14]. By contrast, Japan's highly developed emergency preparedness and response system operating during the 1995 Hanshin earthquake resulted in only six spinal injury cases with neurological deficit, out of a total of 140 reported spinal fractures [15].

In developed as well as developing countries the epidemiological data have shown male dominance in spinal cord injuries [16,17]; however, females were the major victims in the earthquake of Pakistan [18]. It is conjectured that the high proportional risk of injury to which females were exposed may be explained by the fact that the earthquake occurred in the morning when men had already left home for work but most of the women were at the time either inside their homes or rushed back inside their premises to save their children.

The peak incidence of spinal injuries was within the age group 18-40 years comprising of $57 \%$ of the total. In the developing world, this group represents the largest and most significant human resource cohort, constituting the main economic and social fabric of the community. Lumbar-level injuries (48.2\%) were most commonly followed by injuries at the thoracic level $(32.2 \%)$ as observed in the Gujarat earthquake, India, in December 2001 [19] and the Sichuan earthquake, China in May 2008 [20].

With a total population of 725000 and located only $19 \mathrm{~km}$ south-west of the epicentre, Muzaffarabad district accounted for the maximum number of spinal injuries. This was also observed in the Northridge earthquake, United States of America, in January 1994 in which people were prone to injury risk due to the population density and proximity to the epicentre [21].

The post-earthquake response in the disability sector included provision of immediate rehabilitative services, while developing long-term sustainable solutions. Although the majority of spinal cord injury patients have completed their rehabilitation programme, a considerable risk of developing complications yet remains for patients discharged after the initial management and having inadequate follow-up.

The lack of standardized protocols and guidelines for trauma management resulted in several unnecessary amputations, improperly fashioned stumps and peripheral nerve injuries. Many amputations were necessitated due to the gravity of injuries or delayed referrals from remote areas during the first 48 hours. The absence of regulatory norms for manufacturing and fitting prosthetic devices led many unqualified providers to produce substandard prosthesis, causing complications in a number of patients.

The analysis indicated that approximately 581 amputees with major amputations required various kind of prosthesis, contrary to the initial perception echoed by various nongovernmental organizations that "thousands" of artificial limbs were required for rehabilitation of the post-earthquake amputees. It is therefore appropriate to carefully and proactively identify a few qualified institutions that are recognized for designing, manufacturing and fitting prosthetic devices rather than allowing a large number of unskilled organizations that would not be able to perform effectively. Almost all the amputees with lower-limb amputations have been fitted with prosthetic devices; however due to limitations of technology in functional ability and high manufacturing cost, a limited number of amputees with upper-limb amputations were provided with the required prosthesis.

A female predominance was evident among the cases with reported spinal injuries and amputations. In developing countries women with disabilities face stereotypes and challenges posed by their femininity as well as by being a PWD. Out of the total reported victims, $28.6 \%$ were below 18 years age; their observed disability-related functional limitations produced damaging socioeconomic effects on individuals and families and posed disproportionate psychological, emotional, social and financial hardship as they were compelled to cope continuously with the additional burden of providing care and ensuring basic livelihood essentials.

The major challenge was the reintegration of these large numbers of PWDs back into their communities where environmental accessibility, non-availability of essential and rehabilitative health care facilities and attitudinal barriers continued to impede people from reaching their full potential [15]. To surmount these difficulties, a 
regional plan for CBR was designed for the earthquake-affected districts in April 2006, with WHO technical support. The CBR programme has increased public awareness regarding disability issues, improved functional limitations, facilitated the development of targeted livelihood programmes, mandated inclusive education and empowered PWDs through the formation of village CBR committees and disabled people organizations.

The post-earthquake response relating to disabilities was unique as for the first time in the disaster-hit region, an innovative concept combining institutional and community-based rehabilitation was introduced successfully for the pre- and post-earthquake PWDs, with the intervention ultimately leading to the inception of a national CBR programme in the country.

The October 2005 earthquake was a national wake-up call, as it highlighted and brought to the fore the issue of PWDs. It has also provided an opportunity for introspection on the state of disaster management related to disabilities. Many preventable amputations and incomplete spinal cord injuries would not have resulted in permanent damage had there generally been a high level of emergency preparedness and appropriate steps taken for disaster reduction, mitigation and preparedness, particularly in the context of disabilities. Timely and proper referral assumes greatimportancevis-à-visspinalinjuries, which necessitates mandatory training not only for health professionals, but also for front-line rescuers who are the first to reach a disaster site. Pakistan's 2005 earthquake experience should be viewed in relation to the lessons learnt, in order to ensure that lapses in the response and management that occurred are avoided in future unforeseeable adversity.

\section{References}

1. Kuipers P. Disability, health, and international development. Lancet, 2009, 374(9704):1813, 28.

2. Emergency \& humanitarian assistance and the UN convention on the protection and promotion of the rights and dignity of persons with disabilities. Washington DC, International Disability and Development Consortium, 2010 (http://www.iddcconsortium.net/joomla, accessed 16 June 2010).

3. EM-DAT. The international disaster database. Brussels, Centre for Research on the Epidemiology of Disasters, 2006 (http://www. emdat.be/dat.net/disasters/Visualisation/profiles/naturaltable-emdat.php, accessed 24 April 2010).

4. Pakistan earthquake facts and figures sheet - 28 March, 2006. International Federation of Red Cross and Red Crescent Societies, 2005 (http://www.ifrc.org/Docs/pubs/disasters/pakistanear thquake/factsfigures0306.pdf, accessed 15 April 2010).

5. Ahmad T. The population of persons with disabilities in Pakistan. Asia Pacific Population Journal, 1995, 10(1):39-62.

6. Population census by nature of disability 1998. Islamabad, Population Census Organization, Ministry of Economic Affairs and Statistics, 1998.

7. Disability and rehabilitation: WHO action plan 2006-2011. Geneva, World Health Organization, 2006.

8. Kett M, Ommeren MV. Disability, conflict, and emergencies. Lancet, 2009, 374(9704):1801-1803.

9. Despouy L. Human rights and disabled persons (Study Series 6). Geneva, Centre for Human Rights United Nations, 1993.

10. Disaster disability and rehabilitation. Geneva, World Health Organization, Department of Injuries and Violence, 2005.
11. Handicap international rehabilitation activities during Pakistan earthquake 2005. Handicap International, 2006 (http://www. handicap-international.org.uk/, accessed 1 May 2010).

12. Castellano JM. Prehospital management of spinal cord injuries. Emergencies, 2007, 19:25-31.

13. Priebe MM. Spinal cord injuries as a result of earthquakes: lessons from Iran and Pakistan. Journal of Spinal Cord Medicine, 2007, 30(4):367-368.

14. Raissi GR. Earthquake and rehabilitation needs: experiences from Bam, Iran. Journal of Spinal Cord Medicine, 2007, 30:369372.

15. Farooq A et al. Spinal cord injury management and rehabilitation: highlights and shortcomings from the 2005 earthquake in Pakistan. Archives of Physical and Medical Rehabilitation, 2008, 89:579-585.

16. Hoque MF et al. Spinal cord lesions in Bangladesh: an epidemiological study 1994-1995. Spinal Cord, 1999, 37:858-861.

17. Otom AS et al. Traumatic spinal cord injuries in Jordan: an epidemiological study. Spinal Cord, 1997, 35:253-255.

18. Rathore MFA et al. Epidemiology of spinal cord injuries in the 2005 Pakistan earthquake. Spinal Cord, 2007, 45:658-663.

19. Dong $Z U$ et al. Spinal injuries in the Sichuan earthquake. New England Journal of Medicine, 2009, 361:636-637.

20. Shoaf $\mathrm{KI}$ et al. Bourque injuries as a result of California earthquakes in the past decade. Disasters, 1998, 22(3):218-235.

21. Prabhakar MM, Dhaval R, Jadav MB. Management of mass scale dorso-lumbar injuries for early rehabilitation. Asia Pacific Disability Rehabilitation Journal, 2004, 15(1):57-82. 